\title{
The interpretation of in situ soil tests
}

\author{
C. P. WROTH (1984). Géotechnique 34, No. 4, 449-489
}

\section{Professor A. Federico, University of Bari}

On the basis of critical state soil mechanics and, notably, of Wroth's latest deductions, an expression is derived for the undrained strength ratio $c_{\mathrm{u}} / \sigma_{v_{0}}{ }^{\prime}$ in the general case. Further deductions indicate that the expression of the normalized strength ratio for one-dimensional consolidation conditions as given by Wroth is slightly different from that presented here and that the relative difference is higher at higher overconsolidation ratios. The expressions given, as well as Wroth's previous expressions, are similar in form to existing empirical expressions, but they have the advantage of having a theoretical and rational basis.

It is superfluous to emphasize the importance of the possibility of predicting the undrained shear strength of normally or overconsolidated clays. In this context critical state theory (Schofield \& Wroth, 1969) allows rational and acceptable predictions to be made. This possibility has been elegantly pointed out in further detail by Wroth, whose Paper provided the basis for the considerations that are dealt with here and which are essentially limited to the evaluation of peak undrained strength (from triaxial compression) in relation to the consolidation pressure.

Consider conditions of one-dimensional normal consolidation: Fig. 1 shows the lines of consolidation and critical state together with the yield envelope of modified Cam clay. The equation of such an elliptical envelope (given by Wroth) is

$$
q^{2}+M p^{\prime 2}=2 M^{2} p_{\mathrm{K}}{ }^{\prime} p^{\prime}
$$

where $q$ is the deviator stress, $p^{\prime}$ is the average effective stress and $M=6 \sin \phi^{\prime} /\left(3-\sin \phi^{\prime}\right)$.

The ratio of stresses in the sample normally consolidated at $\mathbf{J}$ is given by

$$
\eta_{\mathrm{J}}=\frac{q_{\mathrm{J}}}{p_{\mathrm{J}}^{\prime}}=\frac{3\left(1-K_{0}\right)}{1+2 K_{0}}
$$

The point $\mathbf{J}$ must also lie on the envelope and satisfy equation (1) so that

$$
\left(\eta_{\mathrm{J}}^{2}+M^{2}\right) p_{\mathrm{J}}^{\prime 2}=2 M^{2} p_{\mathrm{K}}^{\prime} p_{\mathrm{J}}^{\prime}
$$

An undrained triaxial test on the sample onedimensionally normally consolidated at $J$ will bring the sample to collapse at $\mathrm{L}$ on the critical state line, without variations in specific volume or water content. The undrained strength is by definition

$$
c_{\mathrm{u}}=\frac{1}{2} q_{\mathrm{L}}=\frac{M}{2} p_{\mathrm{L}}^{\prime}
$$

(for simplicity it is assumed that the peak undrained strength is attained at the critical state), but

$$
\frac{p_{\mathrm{L}}{ }^{\prime}}{p_{\mathrm{J}}^{\prime}}=\left(\frac{p_{\mathrm{K}}{ }^{\prime}}{p_{\mathrm{J}}^{\prime}}\right)^{A}
$$

where the plastic volumetric ratio

$$
A=\frac{\lambda-\kappa}{\lambda}=\frac{C_{\mathrm{c}}-C_{\mathrm{s}}}{C_{\mathrm{c}}}
$$

So, from equation (3) it follows that

$$
\frac{p_{\mathrm{K}}^{\prime}}{p_{\mathrm{J}}^{\prime}}=\frac{\eta_{\mathrm{J}}^{2}+M^{2}}{2 M^{2}}
$$

Denoting the initial consolidation pressure by $\sigma_{\mathrm{vo}}{ }^{\prime}\left(=\sigma_{1 \mathrm{j}}{ }^{\prime}=3 p_{\mathrm{j}}^{\prime} /\left(1+2 K_{0}\right)\right)$

$$
\frac{c_{\mathrm{u}}}{\sigma_{\mathrm{v}_{0}}{ }^{\prime}}=\frac{1+2 K_{0}}{3} \frac{M}{2}\left(\frac{\eta_{\mathrm{J}}{ }^{2}+M^{2}}{2 M^{2}}\right)^{\Lambda}
$$

For isotropic consolidation conditions $\left(K_{0}=1\right.$, $\eta=0$ ), equation (7) becomes

$$
\frac{c_{\mathrm{u}}}{\sigma_{\mathrm{v}}{ }^{\prime}}=\frac{M}{2}\left(\frac{1}{2}\right)^{\wedge}
$$

coinciding with equation (24) of Wroth's Paper where a value of 2 is assumed for $r$ (the spacing ratio of the isotropic consolidation line and the critical state line is $\left.p_{1}^{\prime} / p_{\mathrm{K}}{ }^{\prime}\right)$ and the overconsolidation ratio $R=p_{\mathrm{j}}^{\prime} / p_{\mathrm{B}}^{\prime}=1$.

In the original critical state theory (Schofield \& Wroth, 1969), $r=2.71$ (or the base of natural logarithms), thus producing the well-known expression

$$
\frac{c_{\mathrm{u}_{\mathrm{NC}}}}{\sigma_{\mathrm{v}_{0}}}=\frac{M}{2} \exp (-\Lambda)
$$

The symbol $R$, introduced by Atkinson \& Bransby (1978) as a ratio of average normal 

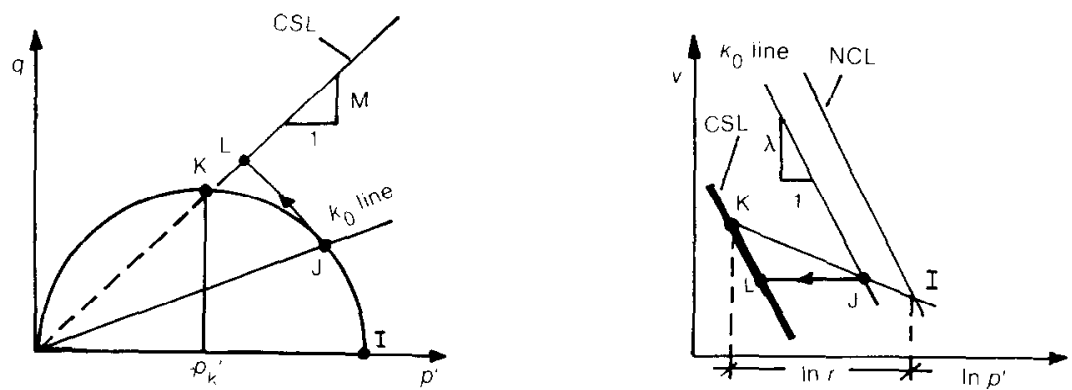

Fig. 1. Consolidation and critical state lines and yield envelope for modified Cam clay

stresses to indicate the overconsolidation in terms of $p^{\prime}$, has a different meaning from the usual overconsolidation ratio OCR (otherwise $R_{0}$ ) of onedimensional conditions. Because $K_{0}$ varies during the overconsolidation, $R$ is, in general, different from OCR. For one-dimensional consolidation conditions (Fig. 2)

$$
R=\frac{p_{\mathrm{J}}^{\prime}}{p_{\mathrm{B}}{ }^{\prime}}=\frac{\sigma_{\mathrm{v} \max }^{\prime}\left(1+2 K_{0}{ }^{N C}\right)}{\sigma_{\mathrm{v}_{\mathrm{B}}}{ }^{\prime}\left(1+2 K_{0}{ }^{\mathrm{OC}}\right)}=\mathrm{OCR} \frac{1+2 K_{0}{ }^{\mathrm{NC}}}{1+2 K_{0}{ }^{\overline{O C}}}
$$

\section{From Fig. 2}

$$
\lambda \ln \left(\frac{p_{\mathrm{L}}{ }^{\prime}}{p_{\mathrm{S}}^{\prime}}\right)=\kappa \ln \left(\frac{p_{\mathrm{J}}^{\prime}}{p_{\mathrm{B}}{ }^{\prime}}\right)
$$

but, according to equation (4)

$$
\begin{aligned}
& p_{\mathrm{L}}^{\prime}=\frac{2 c_{\mathrm{u}_{\mathrm{L}}}}{M}-\frac{2 c_{\mathrm{u}_{\mathrm{J}}}}{M}-\frac{2 c_{\mathrm{uNC}_{\mathrm{N}}}}{M} \\
& p_{\mathrm{s}}^{\prime}=\frac{2 c_{\mathrm{uS}_{\mathrm{S}}}}{M}=\frac{2 c_{\mathrm{u}_{\mathrm{B}}}}{M}=\frac{2 c_{\mathrm{uOC}_{\mathrm{C}}}}{M}
\end{aligned}
$$

from which

$$
\frac{c_{\mathrm{uNC}}}{c_{\mathrm{uOC}}}=\left(\frac{p_{\mathrm{J}}^{\prime}}{p_{\mathrm{B}}^{\prime}}\right)^{\kappa / \lambda}
$$

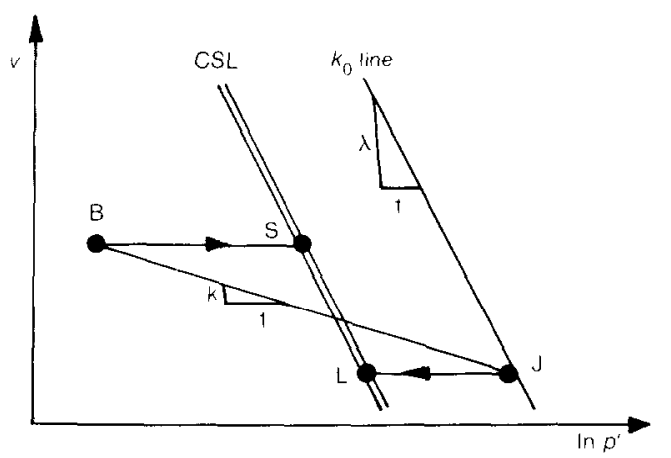

Fig. 2. Failure of specimens consolidated to the same maximum consolidation pressure or, since $\kappa / \lambda=1-A$ (equation (5))

$$
c_{\mathrm{uOC}}=c_{\mathrm{u}_{\mathrm{NC}}}\left(\frac{p_{\mathrm{B}}^{\prime}}{p_{\mathrm{J}}^{\prime}}\right)^{1-\Lambda}
$$

Expression (12) is analogous to that of Atkinson \& Bransby (1978) which was obtained in a less direct way.

From equations (7) and (10), equation (12) can be written

$$
\begin{aligned}
c_{\mathrm{uB}} & =c_{\mathrm{uOC}}=\sigma_{\mathrm{v} j}{ }^{\prime}\left(1+2 K_{0}{ }^{\mathrm{NC}}\right) \frac{M}{6} \\
& \times\left(\frac{\eta_{\mathrm{JNC}^{2}}{ }^{2}+M^{2}}{2 M^{2}}\right)^{\Lambda}\left(\frac{1}{\mathrm{OCR}} \frac{1+2 K_{0}^{\mathrm{OC}}}{1+2 K_{0}^{\mathrm{NC}}}\right)^{1-A}
\end{aligned}
$$

from which, because $\sigma_{\mathrm{v}_{\mathrm{j}}}{ }^{\prime}=\sigma_{\mathrm{v}_{\mathrm{B}}}{ }^{\prime} \mathrm{OCR}$, the general expression for $c_{\mathrm{u}} / \sigma_{\mathrm{v}_{0}}{ }^{\prime}$ in terms of OCR, $K_{0}{ }^{\mathrm{NC}}$, $K_{0}{ }^{O C}, \phi^{\prime}$ and $A$ is

$$
\begin{aligned}
& \frac{\mathcal{c}_{\mathrm{u}}}{\sigma_{\mathrm{v}_{0}}{ }^{\prime}}=\operatorname{OCR}\left(1+2 K_{0}{ }^{\mathrm{NC}}\right) \frac{M}{6} \\
& \quad \times\left(\frac{\eta_{\mathrm{NC}}{ }^{2}+M^{2}}{2 M^{2}}\right)^{\prime}\left(\frac{1}{\mathrm{OCR}} \frac{1+2 K_{0} \mathrm{OC}^{2}}{1+2 K_{0} \mathrm{NC}}\right)^{1-1}
\end{aligned}
$$

or

$$
\frac{c_{\mathrm{u}}}{\sigma_{\mathrm{v}_{0}}{ }^{\prime}}=\left(1+2 K_{0}{ }^{\mathrm{OC}}\right) \frac{M}{6}\left(\frac{\eta_{\mathrm{NC}}^{2} \mid M^{2}}{2 M^{2}}\right)^{A} R^{A}
$$

which, if the soil is normally consolidated, becomes the same as equation (7). For isotropic consolidation conditions $\left(K_{0}=1, \eta=0\right)$

$$
\frac{c_{\mathrm{u}}}{\sigma_{\mathrm{v}_{0}}{ }^{\prime}}=\frac{M}{2}\left(\frac{K}{2}\right)^{A}
$$

as given by Wroth.

Normalizing the undrained strength ratio in the form $\left(c_{\mathrm{u}} / \sigma_{\mathrm{v}_{0}}{ }^{\prime}\right)_{\mathrm{OC}} /\left(c_{\mathrm{u}} / \sigma_{\mathrm{v}_{0}}\right)_{\mathrm{NC}}$

$$
\begin{aligned}
\frac{\left(c_{\mathrm{u}} / \sigma_{\mathrm{vo}}{ }^{\prime}\right)_{\mathrm{OC}}}{\left(c_{\mathrm{u}} / \sigma_{\mathrm{v}}{ }^{\prime}\right)_{\mathrm{NC}}} & =\left(\frac{1+2 K_{0}{ }^{\mathrm{OC}}}{1+2 K_{0}{ }^{\mathrm{NC}}}\right) R^{A}=\mathrm{OCR} R^{A-1} \\
& =(\mathrm{OCR})^{A}\left(\frac{1+2 K_{0}{ }^{\mathrm{OC}}}{1+2 K_{0}{ }^{\mathrm{NC}}}\right)^{1-A}
\end{aligned}
$$

For isotropic consolidation conditions, $\mathrm{OCR}=R$ 
Table 1

\begin{tabular}{c|c|c|c|c|c|c}
\hline & OCR $=1$ & OCR $=2$ & OCR $=5$ & OCR $=10$ & OCR $=20$ & OCR $=50$ \\
\hline$\left[\left(1+2 K_{0}{ }^{\mathrm{OC}}\right) /\left(1+2 K_{0}{ }^{\mathrm{NC}}\right)\right]^{1-A}$ & 1 & 1.06 & 1.17 & 1.26 & 1.37 & 1.55 \\
\hline
\end{tabular}

and equation (15) is the same as Wroth's equation (28), i.e.

$$
\frac{\left.\left(c_{\mathrm{u}} / \sigma_{\mathrm{v}_{0}}\right)^{\prime}\right)_{\mathrm{OC}}}{\left(c_{\mathrm{u}} / \sigma_{\mathrm{v}_{0}}\right)_{\mathrm{NC}}}=R^{\Lambda}
$$

The normalized ratios (15) and (16) remain the same for all $r$ and so they have the advantage of being independent of the spacing ratio $r$ as well as the frictional coefficient $M$.

As emphasized by Wroth the importance of equation (16), which is formally analogous to the empirical expression given by Ladd, Foott, Ishihara, Schlosser \& Poulos (1977), is that if the undrained strength ratio of a clay can be measured or estimated for a normally consolidated specimen, then its value can be predicted for other specimens of the clay provided that the degree of overconsolidation is known', and provided that the constant $A$ is known.

Similar considerations hold for equation (15) where, however, the additional parameters $K_{0}{ }^{\mathrm{NC}}$ and $K_{0}{ }^{\circ \mathrm{C}}$ are present.

It should be noted, however, that for onedimensional consolidation Wroth gives

$$
\frac{\left(c_{\mathrm{u}} / \sigma_{\mathrm{v}_{0}}{ }^{\prime}\right)_{\mathrm{OC}}}{\left(c_{\mathrm{u}} / \sigma_{\mathrm{v}_{\mathrm{o}}}\right)_{\mathrm{NC}}}=(\mathrm{OCR})^{A}
$$

which is valid, strictly, for isotropic conditions $(R=$ OCR). Equations (15) and (17) differ formally by the factor

$$
\left(\frac{1+2 K_{0}^{\mathrm{oC}}}{1+2 K_{0}^{-\mathrm{NC}}}\right)^{1-1}
$$

i.e.

$$
\begin{aligned}
{\left[\frac{\left.\left(c_{\mathrm{u}} / \sigma_{\mathrm{v}_{0}}\right)^{\prime}\right)_{\mathrm{OC}}}{\left(c_{\mathrm{u}} / \sigma_{\mathrm{v}_{0}}\right)_{\mathrm{NC}}}\right]_{K_{0}}=} & {\left[\frac{\left.\left(c_{\mathrm{u}} / \sigma_{\mathrm{v}_{u}}\right)^{\prime}\right)_{\mathrm{OC}}}{\left(c_{\mathrm{u}} / \sigma_{\mathrm{v}_{0}}\right)_{\mathrm{NC}}}\right]_{\kappa=1} } \\
& \times\left(\frac{1+2 K_{0}{ }^{\mathrm{OC}}}{1+2 K_{0}{ }^{\mathrm{NC}}}\right)^{1-A}
\end{aligned}
$$

To evaluate the size of this difference, the empirical expressions of Jaku (1944) and Alpan (1967) can be resorted to, for example, with regard to the $K_{0}$ values. The example is limited to remoulded Weald clay with the values of the soil constants $\phi^{\prime}=24.25^{\circ}$ and $A=0.628$ taken from Table 6.1 of Schofield \& Wroth (1968). The results are given in Table 1 and, although they are within the limits of validity of the empirical expressions used, they indicate that at high overconsolidation ratios the difference may not be negligible.

\section{ACKNOWLEDGEMENTS}

The Author is grateful to Professor R. Nova for helpful discussions on the subject.

This research was supported by the Italian Ministry of Education (grant MPI $60 \%$ n. 84/5047).

\section{REFERENCES}

Alpan, I. (1967). The empirical evaluation of the coefficients $K_{0}$ and $K_{0 R}$. Soils $F d n s$ 7, No. 1, 31-40.

Atkinson, J. H. \& Bransby, P. L. (1978). The mechanics of soils: an introduction to critical state soil mechanics. London: McGraw-Hill.

Jaku, J. (1944). The coefficient of earth pressure at rest. J. Soc. Hung. Arch. Engrs, Oct., 355-358.

Ladd, C. C., Foott, R., Ishihara, K., Schlosser, F. \& Poulos, H. G. (1977). Stress-deformation and strength characteristics. State of the Art Report. Proc. 9th Int. Conf. Soil Mech. Fdn Engng, Tokyo 2, 421-494.

Schofield, A. N. \& Wroth, C. P. (1968). Critical state soil - mechanics. London: McGraw-Hill.

\section{Author's reply}

The Writer has extended the derivation of the formula for the undrained strength ratio from conditions of isotropic overconsolidation to onedimensional consolidation. This development is to be welcomed. However, there is hidden one minor inconsistency, and this concerns the swelling behaviour of clays in the different circum. stances of isotropic and one-dimensional consolidation.

The basic assumption in critical state soil mechanics is that the isotropic normal consolidation and swelling lines are straight in the semilogarithmic plot of Fig. 2, with respective gradients of $-\lambda$ and $-\kappa$.

If, however, the swelling behaviour in onedimensional conditions is also straight in the classical plot of voids ratio $e$ (or specific volume $V$ ) against $\log \sigma_{\mathrm{v}}{ }^{\prime}$ (where $\sigma_{v}{ }^{\prime}$ is the vertical effective stress) then the same results cannot lic on a straight line when plotted as $V$ against $\log p^{\prime}$ (where $p^{\prime}$ is the mean effective stress). This is because in one-dimensional swelling the ratio $\bar{K}_{0}$ is not constant so that $p^{\prime}$ is not proportional to $\sigma_{\mathrm{v}}{ }^{\prime}$.

Consequently the expression (the Author's equation (68))

$$
\frac{p_{1}^{\prime}}{p_{\mathrm{j}}^{\prime}}=\left(\frac{p_{\mathrm{k}}^{\prime}}{p_{\mathrm{i}}^{\prime}}\right)^{A}
$$


is not strictly valid for the one-dimensional case. The error introduced by this inconsistency is small, but increases with the value of the overconsolidation ratio. Unfortunately there are few data available to indicate how significant this discrepancy might be, but the indications are that the difference will reduce the factor

$$
\left(\frac{1+2 K_{0}{ }^{\mathrm{oC}}}{1+2 K_{0}{ }^{\mathrm{NC}}}\right)^{1-A}
$$

established by the Writer. 